\title{
Effects of calcium and nifedipine on noradrenaline- and PGF-2 $\alpha$-induced activity of the ampullary-isthmic junction of the human oviduct in vitro
}

\author{
A. Forman, K.-E. Andersson and U. Ulmsten \\ Department of Obstetrics and Gynecology, Aarhus Kommunehospital, and Department of Clinical \\ Pharmacology, University of Aarhus, DK-8000 Aarhus C, Denmark
}

\begin{abstract}
Summary. From 22 women undergoing hysterectomy at various stages of the menstrual cycle, strip preparations were dissected from the outer, longitudinal and the inner, circular smooth muscle layers of the ampullary-isthmic junction (AIJ). The strips were mounted in organ baths, and isometric tension was recorded. Spontaneous contractions were recorded mainly in circular muscle strips. Contractions were elicited by $127 \mathrm{~mm}$ $\mathrm{K}^{+}, 10^{-6} \mathrm{M}$-noradrenaline and $10^{-6} \mathrm{M}-\mathrm{PGF}-2 \alpha$. Potassium induced biphasic responses that were slightly different in the two tissues. In circular muscle strips, noradrenaline and PGF- $2 \alpha$ induced phasic contractions superimposed on a rise in tone. In longitudinal muscle specimens, the two compounds produced tonic responses. All types of mechanical activity were inhibited by removal of extracellular calcium. $\mathrm{K}^{+}$-induced responses and phasic contractions produced by noradrenaline and PGF- $2 \alpha$ could be abolished by $10^{-6} \mathrm{M}$-nifedipine whereas the tonic contractions in the circular and longitudinal muscle were more resistant to the calcium antagonist. The results suggest that $\mathrm{K}^{+}$-induced responses in circular and longitudinal muscle of the human AIJ, and the phasic contractions in circular muscle, depend on calcium influx via potentialsensitive membrane channels. Receptor-operated calcium channels seem to be involved in the tonic contractions observed mainly in the longitudinal smooth muscle.
\end{abstract}

\section{Introduction}

The transient retention of the ovum/embryo in the ampulla of the human Fallopian tube is a distinct feature of the human reproductive process (Cheviakoff et al., 1976; Croxatto et al., 1978). This delay in oviducal transport suggests a sphincter-like function of the ampullary-isthmic junction and the isthmus. The factors controlling the complex motility pattern of this part of the human oviduct are still largely unknown, but ovarian hormones (Lindblom, Hamberger \& Ljung, 1979a; Marshall, 1981; Helm, Owman, Sjöberg \& Walles, 1982a), local prostaglandin synthesis (VastikFernandez, Gimeno, Luna \& Simeno, 1975; Lindblom, Hamberger \& Wiqvist, 1978) and adrenergic and peptidergic nerves (Lindblom, Ljung \& Hamberger, 1979b; Helm, 1981; Marshall, 1981) may be involved. However, irrespective of the actual agent affecting the smooth muscle cell, a final control of the activity of the contractile proteins is exerted by the concentration of free calcium in the cytoplasm (see Bolton, 1979). Depending on the agonist and the smooth muscle involved, channels of different types in the cell membrane may mediate influx of calcium from the extracellular phase, thereby contributing to the rise in cytoplasmic calcium necessary for the activation of 
contraction. Two main classes of such membrane channels are recognized : one type is activated by changes in membrane potential, the potential-sensitive channels, whereas the other is activated by the agonist-receptor interaction, the receptor-operated channels. The potential-sensitive channels are more or less specifically blocked by calcium antagonists, thereby allowing a differentiation of these mechanisms (Bolton, 1979).

In addition to the membrane channels allowing calcium entry, intracellular sources of calcium may contribute to the cytoplasmic free calcium. In vascular smooth muscle, a significant part of the calcium mediating the noradrenaline response may be released from this source (van Breemen, Farinas, Gerba \& McNaughton, 1972) and, in the myometrium, oxytocin and prostaglandin (PG) F- $2 \alpha$ may release calcium from intracellular stores by a direct action (Carsten, 1974). However, studies on ${ }^{45} \mathrm{Ca}^{2+}$ exchanges in the rabbit oviduct were inconclusive as to the source of the calcium involved in contraction (Hodgson \& Daly, 1976).

The present study was undertaken to investigate the mechanisms of activation of the circular and longitudinal smooth muscle layers of the human ampullary-isthmic junction by examination of the effects of extracellular calcium and the calcium entry blocker, nifedipine, on contractions elicited by noradrenaline, PGF- $2 \alpha$ and potassium depolarization.

\section{Materials and Methods}

Preparations. Fallopian tubes were obtained from 22 women with a mean age of 38 years (range 32-45), undergoing sterilization by salpingectomy or hysterectomy because of myomas. The patients had had regular menstrual cycles, and all specimens were macroscopically normal. The menstrual phase was determined by histological examination of the endometrium. The oviducts were excised with extreme care and the preparations were immediately placed in ice-cold, oxygenated Krebs' solution and taken to the laboratory. The ampullary-isthmic junction was identified by air insufflation into the ampullary end of the tube (Seitchik, Goldberg, Goldsmith \& Pauerstein, 1968). Using transillumination of the specimens under an operating microscope (Zeiss), 3-4 smooth muscle strips (diam. $\sim 0.5 \mathrm{~mm}$, length 3-4 mm) were dissected from the outer, longitudinal layer of the ampullary-isthmic junction along the fibre direction, together with the peritoneal covering of the oviduct. The oviduct was then incised parallel to its long axis, and 3-4 transverse smooth muscle strips (diam. $\sim 0.5 \mathrm{~mm}$, length $3-4 \mathrm{~mm}$ ) were dissected from the inner circular muscle layer. By means of silk ligatures, the strips were mounted horizontally in $5 \mathrm{ml}$ organ baths $\left(37^{\circ} \mathrm{C}\right.$ ) with Krebs' solution (see below) and aerated with $95 \% \mathrm{O}_{2}, 5 \% \mathrm{CO}_{2}$, giving a final $\mathrm{pH}$ of $7 \cdot 40$. Isometric tension was recorded by means of $\mathrm{Grass} \mathrm{Ft} 03$ transducers connected to a Beckman $\mathrm{R} 611$ writer. This procedure was completed within $1 \mathrm{~h}$ of the operation. Initial tension was set at 4 $\mathrm{mN}$, and the preparations were allowed to equilibrate for $1 \mathrm{~h}$. Contractions were then induced by $\mathrm{K}^{+}$every 20 min until reproducible.

While all longitudinal muscle preparations were investigated on the day of the operation, 6 out of 80 circular strips (from 2 patients) were stored overnight at $4^{\circ} \mathrm{C}$ in $\mathrm{Krebs}$ ' solution and studied the following day; these preparations were only used for repeat experiments to check previous results.

Solutions. The normal Krebs' solution consisted of (mM): $\mathrm{NaCl} 119, \mathrm{KCl} 4 \cdot 6, \mathrm{NaHCO}_{3} 15$, $\mathrm{CaCl}_{2} 1 \cdot 5, \mathrm{MgCl}_{2} 1 \cdot 2, \mathrm{NaH}_{2} \mathrm{PO}_{4} 1 \cdot 2$, glucose 11. The $\mathrm{K}^{+}$depolarizing $\mathrm{Krebs}$ solution contained (mM): $\mathrm{KCl} 127, \mathrm{NaHCO}_{3} 15, \mathrm{CaCl}_{2} 1 \cdot 5, \mathrm{MgCl}_{2}$ 1.2, $\mathrm{NaH}_{2} \mathrm{PO}_{4} 1 \cdot 2$, glucose 11. In 'Ca-free' solutions $\mathrm{CaCl}_{2}$ was omitted, and $0.01 \mathrm{~mm}$-EGTA was added.

Drugs used. The PGF-2 $\alpha$ (Dinoprost) was from Upjohn, Crawley, U.K., the noradrenaline (Noradrenaline) from DAK, Copenhagen, Denmark, the propranolol (Inderal) from ICI, Manchester, U.K., and nifedipine (Adalat) was from Bayer AG, Leverkusen, West Germany. Concentrations are given as final bath concentrations. 


\section{Results}

\section{Spontaneous contractions}

In circular muscle preparations, a more or less regular spontaneous activity developed within 1 $\mathrm{h}$ of equilibration (Text-fig. 1). In a few strips, these contractions gradually decreased but spontaneous activity mostly continued throughout the experiment. Storage overnight did not qualitatively affect the spontaneous activity or the reaction to drugs.

In longitudinal muscle preparations, spontaneous activity occurred less frequently and only during the initial part of the experiment. After storing overnight at $4{ }^{\circ} \mathrm{C}$ in $\mathrm{Krebs}$ ' solution, more regular spontaneous contractions could be registered, often superimposed on variations in basic tone. All experiments on longitudinal muscle were performed on the day of the operation.

No qualitative differences in spontaneous contractile activity or reactions to drugs were observed in preparations obtained at different stages of the menstrual cycle.
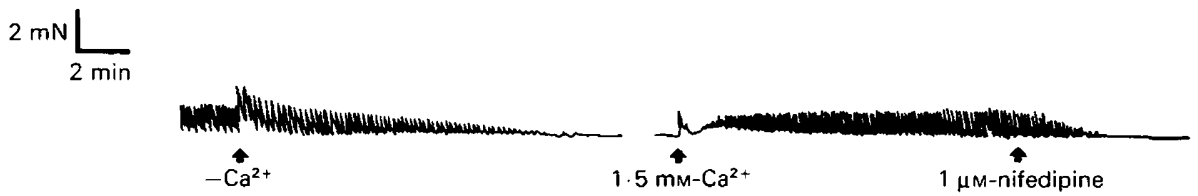

Text-fig. 1. Effects on spontaneous contractions of circular muscle of withdrawal of $\mathrm{Ca}^{2+}$ $\left(-\mathrm{Ca}^{2+}\right)$, restoration of $\mathrm{Ca}^{2+}$ or treatment with nifedipine.

\section{$K^{+}$-induced contractions}

In longitudinal muscle strips, depolarization with $\mathrm{K}^{+}(127 \mathrm{mM})$ induced an initial rapidly developing tension peak which gradually declined to a lower steady tone (Text-fig. 2). In circular muscle strips, the initial response to $\mathrm{K}^{+}(127 \mathrm{mM})$ was a transient rapidly developing contraction, and then tension declined to the base line. With prolonged $\mathrm{K}^{+}$depolarization, a second slow increase in tone was seen, reaching a steady level in $15 \mathrm{~min}$.

When the $\mathrm{K}^{+}$-induced response was limited to the initial peak, this could be reproduced at 20min intervals in both types of strips. However, responses to prolonged exposures ( $>5 \mathrm{~min}$ ) to $\mathrm{K}^{+}$ (127 mM), allowing the sustained phases to develop, were not consistently reproducible.

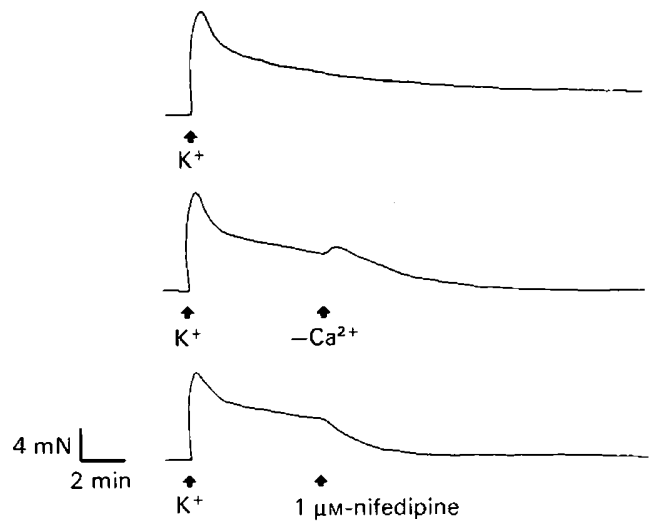

Text-fig. 2. Effects of withdrawal of $\mathrm{Ca}^{2+}\left(-\mathrm{Ca}^{2+}\right)$ or treatment with nifedipine on $\mathrm{K}^{+}$-induced responses of longitudinal muscle strips from the same Fallopian tube. 


\section{Noradrenaline-induced contractions}

The experiments involving noradrenaline were performed in the presence of $10 \mu \mathrm{M}$-propranolol, a concentration that by itself did not influence the spontaneous activity of the muscles.

In longitudinal muscle strips, $0 \cdot 01-0 \cdot 1 \mu \mathrm{M}$-noradrenaline induced a mainly tonic response, sometimes with superimposed, phasic contractions. At concentrations of 1-10 $\mu \mathrm{M}$, the drug produced an initial tension peak which slowly decreased. In circular muscle strips $0.01-0.1 \mu \mathrm{M}-$ noradrenaline enhanced spontaneous contractions. At higher concentrations of noradrenaline (1$10 \mu \mathrm{M}$ ), these contractions were superimposed on a rise in tone (Text-fig. 3a, b). At repeated exposures to $1 \mu \mathrm{M}$-noradrenaline, the induced contraction amplitudes decreased slightly (about $5 \%$ ) in the circular and longitudinal muscle preparations.

\section{Contractions induced by $P G F-2 \alpha$}

In longitudinal muscle strips, $0 \cdot 01-10 \mu \mathrm{M}-\mathrm{PGF}-2 \alpha$ induced a mainly tonic contraction which gradually decreased (Text-fig. 3c). In circular muscle strips $0 \cdot 05-0 \cdot 1 \mu \mathrm{M}-\mathrm{PGF}-2 \alpha$ enhanced spontaneous activity. At higher concentrations of the hormone $(1-10 \mu \mathrm{M})$, the phasic contractions were superimposed on an increased basal tone (Text-fig. 3d). At repeated stimulation with $1 \mu \mathrm{M}-\mathrm{PGF}-2 \alpha$ there was a decrease of about $5 \%$ of the contraction amplitudes in both types of preparation.
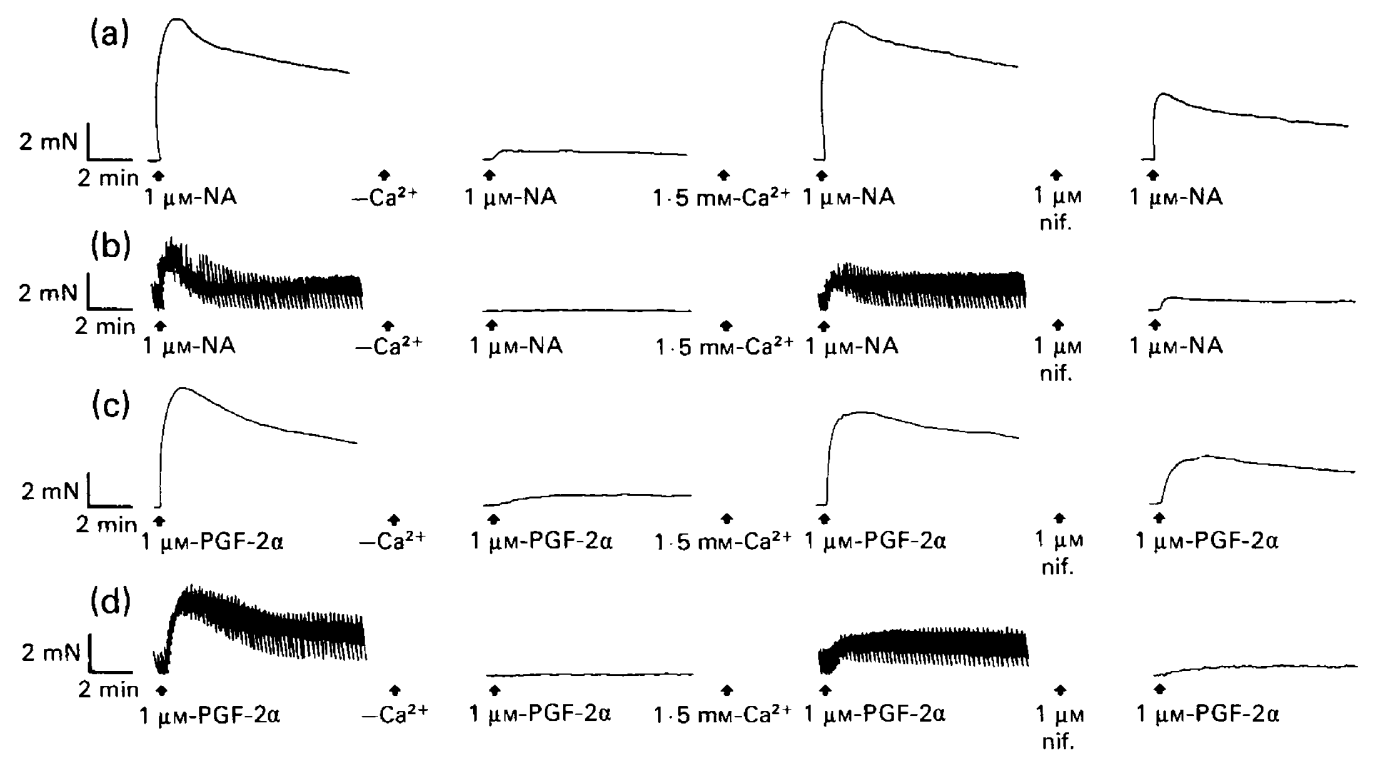

Text-fig. 3. Effects on responses of $(a, c)$ longitudinal and $(b, d)$ circular muscle strips from the same Fallopian tubes to $(a, b)$ noradrenaline and $(c, d)$ PGF- $2 \alpha$. NA, noradrenaline $(10 \mu \mathrm{M}$ propranolol added); $-\mathrm{Ca}^{2+}$, withdrawal of $\mathrm{Ca}^{2+}$; nif., pretreatment with nifedipine for 15 min.

\section{Effects of removal of calcium}

Spontaneous activity. In the circular muscle preparations, spontaneous activity was abolished 10-15 min after changing the medium to 'calcium-free' Krebs' solution (Text-fig. 1). When calcium $(1.5 \mathrm{mM}$ ) was added to the medium, the spontaneous activity recovered within $15 \mathrm{~min}$ (Text-fig. 1).

$\mathrm{K}^{+}$-induced contractions. After changing the medium to calcium-free solution, the initial peak of the $\mathrm{K}^{+}$-induced response was abolished within $20 \mathrm{~min}$ in the circular and longitudinal muscle strips. Addition of calcium restored the tension peak of the $\mathrm{K}^{+}$-induced contraction within $20 \mathrm{~min}$ 
in longitudinal muscle strips, and after about $40 \mathrm{~min}$ in circular muscle strips. Removal of calcium during the development of the sustained phase relaxed both longitudinal (Text-fig. 2), and the circular strips completely.

Contractions induced by noradrenaline and PGF-2 $\alpha$. After $20 \mathrm{~min}$ in calcium-free medium the responses to $1 \mu \mathrm{M}$-noradrenaline and $1 \mu \mathrm{M}$-PGF- $2 \alpha$ in longitudinal muscle strips were nearly abolished, leaving a small increment in tone (Text-fig. $3 \mathrm{~b}, \mathrm{~d}$ ). In circular muscle strips, neither of the two components of the responses to noradrenaline or PGF- $2 \alpha$ could be elicited. Readdition of calcium $(1.5 \mathrm{mM})$ to the solution restored the responses to the two compounds in both preparations almost completely within $10 \mathrm{~min}$ (Text-fig. $2 \mathrm{a}, \mathrm{c}$ ).

\section{Effects of nifedipine}

Spontaneous contractions in the circular muscle preparations were abolished by $1 \mu \mathrm{M}$-nifedipine (Text-fig. 1).

$K^{+}$-induced contractions. In longitudinal and circular muscle strips, the initial tension peak of the $\mathrm{K}^{+}$-induced contraction was inhibited in a concentration related manner by pretreatment with nifedipine $(2.9 \mathrm{nM}-2.9 \mu \mathrm{M})$ for $15 \mathrm{~min}$. When given at the sustained phase of the $\mathrm{K}^{+}$-induced contractions, $1 \mu \mathrm{M}$-nifedipine relaxed longitudinal (Text-fig. 2), and circular muscle preparations completely.

Contractions induced by noradrenaline and PGF-2 $\alpha$. Pretreatment of the longitudinal muscle preparations with $1 \mu \mathrm{M}$-nifedipine decreased the response to $1 \mu \mathrm{M}$-noradrenaline by $30-50 \%$, and also slightly reduced contractions induced by $1 \mu \mathrm{M}-\mathrm{PGF}-2 \alpha$ (Text-fig. $3 \mathrm{a}, \mathrm{c}$ ). In circular muscle preparations, the phasic activity induced by $1 \mu \mathrm{M}$ noradrenaline or PGF- $2 \alpha$ was always abolished by pretreatment with $1 \mu \mathrm{M}$-nifedipine for $15 \mathrm{~min}$, while the increase in tone produced by the two compounds was only partly decreased (Text-fig. $3 \mathrm{~b}, \mathrm{~d}$ ).

\section{Discussion}

Despite the close anatomical proximity of the two smooth muscle layers of the human ampullaryisthmic junction, major differences in functional properties have been demonstrated between the two tissues (Lindblom et al., 1978, 1979a). In accordance with these studies, the present results characterized the inner, circular smooth muscle of the human ampullary-isthmic junction as spontaneously active, and responding to PGF- $2 \alpha$ and $\alpha$-adrenoceptor stimulation by a phasic contraction, superimposed on a rise in tone at higher concentrations of the agonists. In contrast, these drugs produced mainly tonic contractions in longitudinal muscle strips. In the present investigation, this difference between the two preparations was further emphasized by the absence of regular spontaneous activity in the longitudinal smooth muscle, a finding that differs from those of other investigators (Lindblom et al., 1978, 1979a; Helm, 1981). Differences in dissection and mounting techniques may account for this, because the handling of the tissues may affect the local prostaglandin synthesis (Harper, Coons, Radicke, Hodgson \& Valenzuela, 1980).

The dependence of the mechanical activity of smooth muscle on extracellular calcium may be taken as an index for the relative importance of superficial and intracellular calcium pools in the excitation-contraction coupling (Devine, Somlyo \& Somlyo, 1972). The responses to $\mathrm{K}^{+}$in the circular and longitudinal muscle preparations were rapidly abolished by removal of extracellular calcium, suggesting the involvement of a loosely bound calcium pool in the activation process. Nifedipine inhibited the initial peak as well as the tonic phase in both preparations, favouring the view that calcium influx via potential-sensitive channels was an important mechanism for the contraction.

Removal of external calcium rapidly abolished the responses to PGF- $2 \alpha$ in the circular and longitudinal smooth muscle preparations. This finding does not support the view that PGF-2 $\alpha$ acts 
on intracellular calcium stores in human oviducal muscle. The contractions elicited by noradrenaline in the presence of propranolol in both layers of the human ampullary-isthmic junction were also rapidly abolished by removal of extracellular calcium.

$\alpha$-Adrenoceptors can be classified into $\alpha_{1}$ - and $\alpha_{2}$-subtypes according to their relative affinity for drugs that selectively stimulate or block $\alpha$-receptors (Berthelsen \& Pettinger, 1977; Wikberg, 1979; Starke, 1981). It has been suggested that both types of $\alpha$-receptors occur in the human ampullary-isthmic junction (Helm et al., 1982b). Evidence from several tissues suggests that $\alpha_{1}$ receptor stimulation is associated with calcium influx, whereas $\alpha$-receptor mediated activation is related to an inhibition of adenylate cyclase (Wikberg, 1979, 1982; Fain \& Garcia-Sainz, 1980). Irrespective of the $\alpha$-receptor subtype involved in the contractile response to noradrenaline in the human ampullary-isthmic junction, transmembrane calcium influx seems to be an important step in the activation process leading to the contractions. The calcium antagonist nifedipine effectively abolished only the phasic part of the noradrenaline-induced response in the circular muscle preparations, suggesting that the calcium influx involved in this component of the contraction passes through potential-sensitive channels. The possibility of a more or less specific association between the subtypes of $\alpha$-receptor in the cell membrane and the calcium entry mechanisms in the human ampullary-isthmic junction awaits further investigation.

As reported by Lindblom et al. (1978), no qualitative differences in the responses to noradrenaline and PGF- $2 \alpha$ or the sensitivity to nifedipine were observed between tissues investigated at different stages of the menstrual cycle. However, this does not preclude the possibility of there being minor quantitative cyclic variations in the contractile pattern and sensitivity to calcium entry blockade.

It has been suggested that the main site of action for calcium antagonists like nifedipine should be interference with intracellular mechanisms, possibly the calcium-calmodulin interaction (Boström, Ljung, Mårdh, Farsen \& Thulm, 1981). The present results showed that nifedipine was effective in counteracting only the phasic component of contractions induced in circular muscle strips by noradrenaline or PGF-2 $\alpha$. The tonic part of the contractions in circular muscle preparations and the tonic contractions induced in longitudinal muscle strips were more resistant to the calcium antagonist, findings consistent with those of Golenhofen (1981). If the cytoplasmic free calcium concentration is accepted as the main regulator of the contractile protein activity, such a specific effect of nifedipine on certain components of a contractile response seems incompatible with a main effect of the compound on the calmodulin step. In the human ampullary-isthmic junction, therefore, the most important site of action of nifedipine appears to be at the membrane level. Accordingly, the present results suggest calcium influx through potential-sensitive channels in the circular smooth muscle cell membrane as an important step in the activation of spontaneous contractions as well as of phasic contractile activity induced by PGF- $2 \alpha$ and $\alpha$-receptor stimulation. Tonic contractile activation in both muscle layers of the human ampullary-isthmic junction elicited by these agents seems more dependent on receptor-operated channels not readily blocked by calcium antagonists such as nifedipine.

\section{References}

Berthelsen, S. \& Pettinger, W.A. (1977) A functional basis for classification of $\alpha$-adrenergic receptors. Life Sci. 21, 595-606.

Bolton, T.B. (1979) Mechanisms of action of transmitters and other substances on smooth muscle. Physiol. Rev. 59, 606-718.

Boström, S.-L., Ljung, B., Màrdh, S., Farsen, S. \& Thulm, E. (1981) Interaction of the antihypertensive drug felodipine with calmoduline. Nature, Lond. 292, 777778 .
Carsten, M.E. (1974) Prostaglandin and oxytocin: their effects on uterine smooth muscle. Prostaglandins 5, $33-40$.

Cheviakoff, S., Dioz, S., Carril, M., Patritti, N., Croxatto, H.D., Llados, C., Ortiz, M.E. \& Croxatto, H.B. (1976) Ovum transport in women. In Ovum Transport and Fertility Regulation, pp. 416-424. Eds M. J. K. Harper, C. J. Pauerstein, C. E. Adams, E. M. Coutinho, H. B. Croxatto \& D. M. Paton. Scriptor, Copenhagen. 
Croxatto, H.B., Ortiz, M.E., Dioz, S., Hess, R., Balmoceda, J. \& Croxatto, H.D. (1978) Studies on the duration of egg transport by the human oviduct. $A m . J$. Obstet. Gynec. 132, 629-634.

Devine, C.E., Somlyo, A.V. \& Somlyo, A.P. (1972) Sarcoplasmic reticulum and excitation-contraction coupling in mammalian smooth muscles. J. Cell Biol. 52, 690-718.

Fain, J.N. \& Garcia-Sainz, J.A. (1980) Role of phosphatidylinositol turnover on alpha $\mathrm{a}_{1}$, and of adenylate cyclase inhibition in alpha ${ }_{2}$ effects of catecholamines. Life Sci. 26, 1183-1194.

Golenhofen, K. (1981) Differentiation of calcium activation processes in smooth muscle using selective antagonists. In Smooth Muscle, pp. 157-170. Eds E. Bulbring, A. F. Brading, A. W. Jones \& T. Tomita. Edward Arnold, London.

Harper, M.J.K., Coons, L.W., Radicke, D.A., Hodgson, B.J. \& Valenzuela, G. (1980) Role of prostaglandins in contractile activity of the ampulla of the rabbit oviduct. Am. J. Physiol. 238, E157-E166.

Helm, G. (1981) Adrenergic and peptidergic neuromuscular mechanisms in the human Fallopian tube, with special regard to cyclic influences. Thesis, Studenterlitteratur, Lund.

Helm, G., Owman, C.H., Sjöberg, N.-O. \& Walles, B. (1982a) Motor activity of the human Fallopian tube in vitro in relation to plasma concentration of oestradiol and progesterone, and the influence of noradrenaline. J. Reprod. Fert. 64, 233-242.

Helm, G., Owman, C., Sjöberg, N.-O. \& Walles, B. (1982b) Quantitative pharmacological characterization of beta-receptors and two types of alpha-receptors mediating sympathomimetic smooth muscle response in the human Fallopian tube at various cyclic stages. Acta physiol. scand. 114, 425-432.

Hodgson, B.J. \& Daly, S. (1976) The role of calcium in contraction of the oviduct. In Ovum Transport and Fertility Regulation, pp. 182-196. Eds M. J. K. Harp- er, C. J. Pauerstein, C. E. Adams, E. M. Coutinho, H. B. Croxatto \& D. M. Paton. Scriptor, Copenhagen.

Lindblom, B., Hamberger, L. \& Wiqvist, N. (1978) Differentiated contractile effects of prostaglandins $E$ and $F$ on the isolated circular and longitudinal smooth muscle of the human oviduct. Fert. Steril. 30, 553-559.

Lindblom, B., Hamberger, L. \& Ljung, B. (1979a) Contractile patterns of isolated oviductal smooth muscle under different hormonal conditions. Fert. Steril. 33, 283-287.

Lindblom, B., Ljung, B. \& Hamberger, L. (1979b) Adrenergic and novel non-adrenergic neuronal mechanisms in the control of smooth muscle activity in the human oviduct. Acta physiol. scand. 106, 215-220.

Marshall, J.M. (1981) Effects of ovarian steroids and pregnancy on adrenergic nerves of uterus and oviduct. Am. J. Physiol. 240, C165-C174.

Seitchik, J., Goldberg, E., Goldsmith, J.P. \& Pauerstein, C. (1968) Pharmacodynamic studies of the human Fallopian tube in vitro. Am. J. Obstet. Gynec. 102, 727-735.

Starke, K. (1981) $\alpha$-Adrenoceptor subclassification. Rev. Physiol. Biochem. Pharmac. 88, 199-236.

van Breemen, C., Farinas, B.R., Gerba, P. \& McNaughton, E.D. (1972) Excitation-contraction coupling in rabbit aorta studied by the lanthanum method for measuring cellular calcium influx. Circ. Res. 30, 4454.

Vastik-Fernandez, J., Gimeno, M.F., Luna, F. \& Simeno, A.L. (1975) Spontaneous motility and distribution of prostaglandins in different segments of human Fallopian tubes. Am. J. Obstet. Gynec. 122, 663-668.

Wikberg, J.E.S. (1979) The pharmacological classification of adrenergic $\alpha_{1}$ and $\alpha_{2}$ receptors and their mechanisms of action. Linköping University Medical Dissertations, No. 68.

Wikberg, J.E.S. (1982) Adrenergic receptors : classification, ligand binding and molecular properties. Acta med. scand. Supplement 665, 19-36.

Received 2 July 1982 